\title{
1
}

\section{Epidemiology of}

Community-Acquired

Pneumonia Outside

\section{Hospital}

\section{THEO JM VERHEIJ}

Department of General Practice, Julius Center for Health Sciences and Primary Care, University Medical Center Utrecht, Utrecht, The Netherlands

\section{Introduction}

Information on community-acquired pneumonia (CAP) outside hospital is somewhat hampered by the use of different definitions. The International Classification of Primary Care indicates that the diagnosis pneumonia should be coded in the presence of signs of consolidation in lung tissue, either by physical examination or on a chest X ray (Bridges-Webb, 1998). Other publications define pneumonia as the presence of an infiltrate on a chest-X-ray or are just based on the diagnosis stated by the primary care physician. Appraising the literature on the epidemiology of CAP, the reader should realize that different definitions are used by the different sources.

\section{Incidence and Complications}

The incidence of CAP in primary care is reported to be between five and ten cases per 1000 patients per year on average, but highly dependent on age (www.RIVM.nl/ vtv [accessed 2007]). Children up until 4 years of age show an incidence rate of around 20 per 1000 patients per year, after that age incidence drops to approximately one to four per 1000 per year in young adults and after the age of 40

Community-Acquired Pneumonia: Strategies for Management Edited by Antoni Torres and Rosario Menéndez (C) 2008 John Wiley \& Sons, Ltd 
gradually rising to about 15 to 30 per 1000 in the 75 to 79 age group and between 40 and 60 in people over 85 years of age. Incidence rates are higher in men then in women (Figure 1.1).

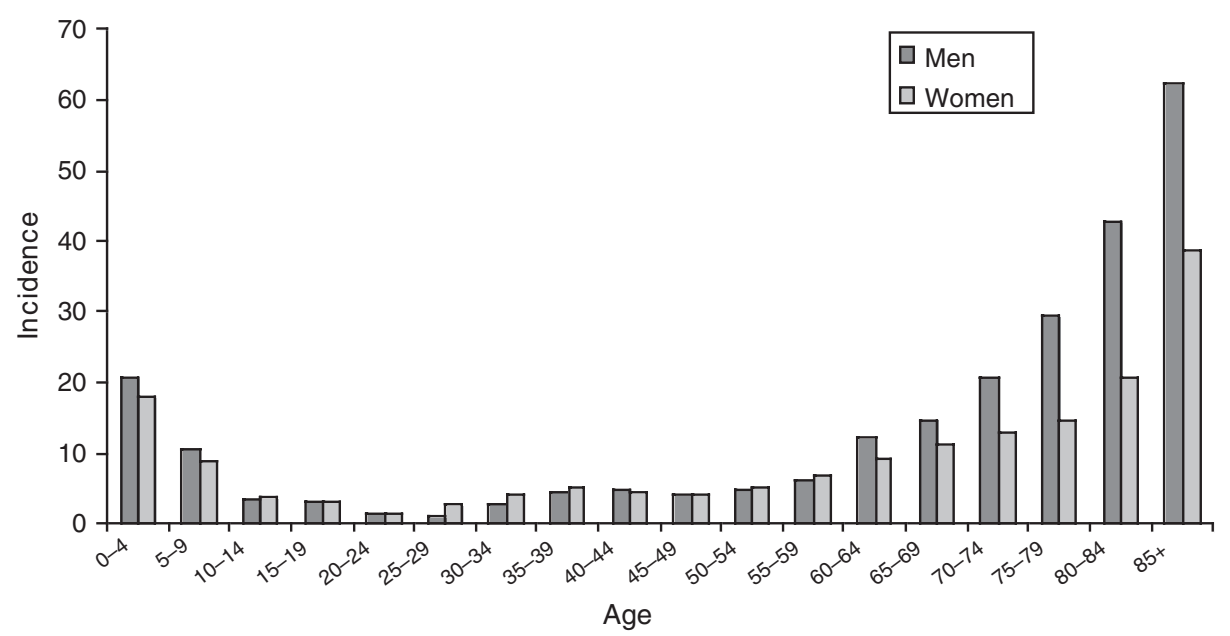

Figure 1.1

Incidence (per 1000 patients per year) of community-acquired pneumonia. (Source: RIVM National Kompas Volksgezondheid; http://www.rivm.nl/vtv/object_document/o1848 n18080.html)

Usually it takes 2 to 4 weeks for the clinical syndrome to dissolve. Overall mortality of CAP in ambulatory patients is assumed to be between 3 and $5 \%$ (Fine et al., 1996; Bont et al., 2007). Hospital admission rates differ somewhat between countries due to different routines and patient expectations. In The Netherlands around $15 \%$ of patients with CAP are admitted to hospital.

\section{Risk Factors for Pneumonia}

There are not many studies available that can provide an answer to the question of who is at risk from getting pneumonia. Obviously age and male gender are risk factors, as can be seen in Figure 1.1. In a Finnish study, alcoholism, chronic lung disease, immunosuppressive therapy, heart disease and institutionalism were found to be risk factors (Koivula et al., 2000). Having chronic lung disease was also found in a British study, and an American study showed that smoking and overweight were independent risk factors for getting pneumonia (Baik et al., 2000; Farr et al., 2000). A recent Dutch study showed that patients with diabetes also have an elevated risk for pneumonia (Muller et al., 2005).

In summary one can say that apart from age, smoking and comorbid conditions, chronic lung diseases in particular, are the most important risk factors for CAP in 
outpatients. In addition, alcohol abuse and immunosuppressive therapy enhances the risk for pneumonia.

\section{Prognosis of Patients with Pneumonia}

Although it is important to know which patients are at risk for getting pneumonia, in daily practice it is even more relevant to know which patients who actually have pneumonia are at risk for complications. As pointed out in Chapter 2, numerous studies have been done on assessment of disease severity in hospitalized patients. The information available on primary care patients is much less abundant.

The most used prediction models in patients with lower respiratory tract infections are the so-called Pneumonia Severity Score (PSI) and the CURB-65 score. The PSI score is developed in hospital patients and contains some measurements such as $\mathrm{pH}$ and urea and sodium levels in blood that are not feasible in a primary care setting (Fine et al., 1997). From the CURB-65 score a simplified CRB-65 is derived that was validated in a cohort of both in- and outpatients (Bauer et al., 2006). This CRB-65 rule, however, only predicts mortality that is an uncommon complication in outpatients with CAP. Second, application of the rule means that every patient over 65 should be admitted to hospital, which is probably not necessary. Some other studies in primary care showed that apart from high age, confusion and blood pressure (the CRB-65 criteria), co-morbid conditions, in particular insulin-dependent diabetes and cardiac failure, hospitalization in the previous year, and the presence of tachypnoea also were predictive for a complicated course, hospitalization and death (Seppa et al., 2001; Bont et al., 2007).

In short, the CRB-65 can be used in primary care patients, but other factors such as comorbidity and certain signs and symptoms should also be taken into account when assessing a patient's risk for complications.

\section{Conclusions}

Valid scientific information on important clinical issues regarding CAP outside hospital is scarce. Community-acquired pneumonia is a rather common disease in primary care, with more pronounced incidence rates in the very young and the very old. Important complications such as hospitalizations and death occur rather frequently in the very old, especially in those with chronic conditions. More studies should be done on occurrence and prognosis of CAP in primary care.

\section{References}

Baik I, Curhan GC, Rimm EB, Bendich A, Willett WC, Fawzi WW. 2000. A prospective study of age and lifestyle factors in relation to community-acquired pneumonia in US men and women. Arch Intern Med 160(20): 3082-3088. 
Bauer TT, Ewig S, Marre R, Suttorp N, Welte T. 2006. CRB-65 predicts death from community-acquired pneumonia. J Intern Med 260(1): 93-101.

Bont J, Hak E, Hoes AW, Schipper M, Schellevis FG, Verheij TJ. 2007. A prediction rule for elderly primary-care patients with lower respiratory tract infections. Eur Respir J 29(5): 969-975.

Bridges-Webb C (ed.). 1998. ICPC-2 The International Classification of Primary Care, an Introduction. Oxford (UK): Oxford University Press.

Farr BM, Woodhead MA, Macfarlane JT, et al. 2000. Risk factors for community-acquired pneumonia diagnosed by general practitioners in the community. Respir Med 94(5): $422-427$.

Fine MJ, Smith MA, Carson CA, et al. 1996. Prognosis and outcomes of patients with community-acquired pneumonia. A meta-analysis. J Am Med Assoc 275(2): 134-141.

Fine MJ, Auble TE, Yealy DM, et al. 1997. A prediction rule to identify low-risk patients with community-acquired pneumonia. $N$ Engl J Med 336(4): 243-250.

Koivula I, Sten M, Makela PH. 1994. Risk factors for pneumonia in the elderly. Am J Med 96(4): 313-320.

Muller LM, Gorter KJ, Hak E, et al. 2005. Increased risk of common infections in patients with type 1 and type 2 diabetes mellitus. Clin Infect Dis 41(3): 281-288.

Seppa Y, Bloigu A, Honkanen PO, Miettinen L, Syrjala H. 2001. Severity assessment of lower respiratory tract infection in elderly patients in primary care. Arch Intern Med 161(22): 2709-2713. 